\title{
Effect of the Fineness of Artificial Pozzolana (Sarooj) on the Properties of Lime-Pozzolana Mixes
}

\author{
Abdel Wahid Hago, Amer Ali Al-Rawas and Awadh Al-Sidairi
}

Department of Civil Engineering, College of Engineering, Sultan Qaboos University, P.O.Box 33, Al Khod 123, Muscat, Sultanate of Oman, Email: ahago@squ.edu.om.
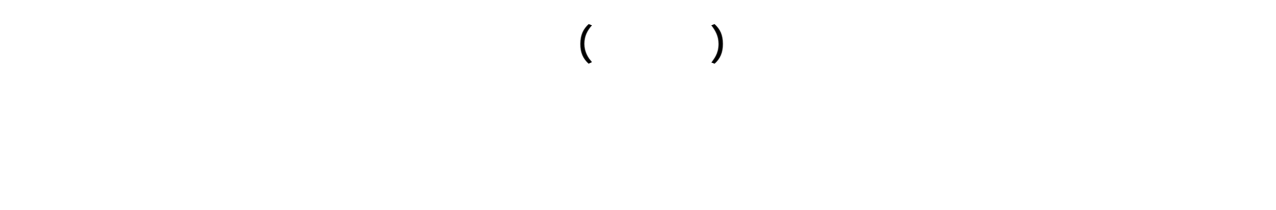

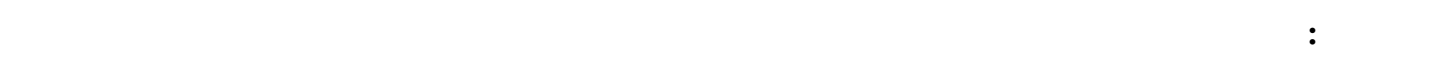

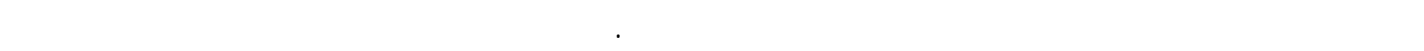

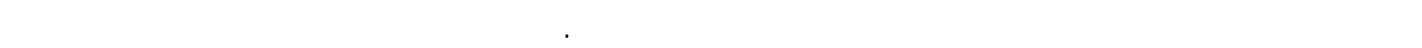

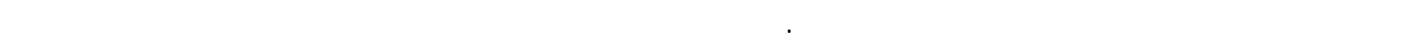

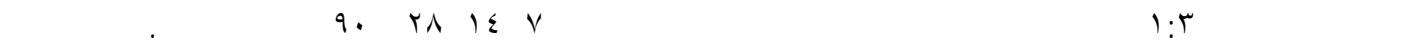

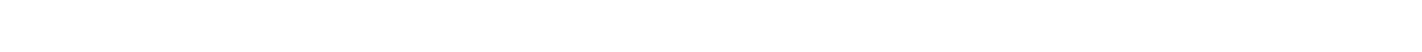

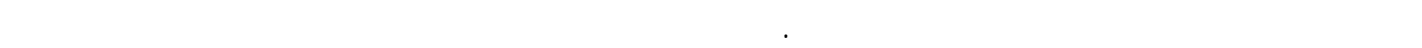
زيادة نمو قوة تحمل الخطلت الصاروجية على المدى الطويل.

\begin{abstract}
Strength development of lime-pozzolana mortars is affected by the fineness of the pozzolan. This paper examines the effect of the fineness of artificial pozzolana on the strength development of lime-pozzolana mixtures. An artificial pozzolana produced by calcining clays from Oman was used in this study. The artificial pozzolana is locally known as "Sarooj", and is currently being used in a big project for the restoration of historical monuments undertaken by the Omani Ministry of National Heritage and Culture. The artificial pozzolana was ground to various degrees of fineness, blended with hydrated lime with a ratio of 3:1, and the resulting mortar was used to make hardened mortar cubes. Strength of mortar cubes was measured at ages of 7, 14, 28 and 90 days of casting. The experimental results show that good artificial pozzolanas show a linear correlation between the Blaine fineness of the artificial pozzolana and the compressive strength, but such relationship does not exists for weak type pozzolanas. The fineness of the artificial pozzolana has its most significant effect on delayed strength gain, with more pronounced effect for good type pozzolan.
\end{abstract}

KEY WORDS: Pozzolana, Sarooj, Cement, Strength Tests, Chemical Tests.

\section{Introduction}

$\mathbf{S}^{\mathrm{a}}$ arooj is an artificial pozzolan produced by burning clays and is used as a cementing material by adding lime and water. In Oman, sarooj has been used for thousands of years in buildings, forts and aflaj (plural of falaj which is defined as a system of distributing water to a village by gravity through built channels). Worldwide, materials like sarooj are known for their good low permeability and long durability. For this reason, sarooj was extensively used in hydraulic structures. Even in this century and with the ready availability of Portland cements, special plants were erected to produce materials like sarooj for major dams in the world, like the Aswan dam in Egypt and the Bhakra dam in India. 
When a mixture of Portland cement and a pozzolana reacts, the pozzolanic reaction progresses like an acid-base reaction of lime and alkalies with the oxides $\left(\mathrm{SiO}_{2},+\mathrm{Al}_{2} \mathrm{O}_{3}+\mathrm{Fe}_{2} \mathrm{O}_{3}\right)$ of the pozzolana. Two things happen: First, there is a gradual decrease in the amount of free calcium hydroxide with time, and second, there is an increasing formation of calcium silicates hydrates $(\mathrm{CSH})$ and calcium aluminosilicates that are similar to the products of hydration of portland cement. According to Lea (1971), the partial replacement of portland cement by pozzolana of high $\mathrm{SiO}_{2} / \mathrm{R}_{2} \mathrm{O}_{3}$ ratio has been found to increase the resistance of concrete to sulfate and sea water attack $\left(\mathrm{R}_{2} \mathrm{O}_{3}\right.$ is approximately the summation of the $\mathrm{Al}_{2} \mathrm{O}_{3}$ and $\mathrm{Fe}_{2} \mathrm{O}_{3}$ contents). This is in part attributable to the removal of free calcium hydroxide formed in the hydration of portland cements by combination with the pozzolana. The end result will be that the paste will contain less calcium hydroxide and more CSH and other products of low porosity. Research on the hydration of blended cements made with natural pozzolanas of volcanic origin (Santorin earth pozzolana) has confirmed that rather than the chemical manifestation, the physical manifestation of the pozzolanic reaction involving pore refinement of the cement paste is probably more important for the enhancement of chemical durability and mechanical strength. The shape, fineness, particle size distribution, density, and composition of pozzolana particles influence the properties of freshly mixed unhardened mortar, and the strength development of the hardened mortar. Most pozzolanas tend to increase the water requirement in the normal consistency test, as a result of their micro-porous character and high surface area, when employed as an ingredient of Portland-pozzolana cements or as admixtures to Portland-cement (ACI-91-M42).

Increasing the fineness of a natural pozzolan or cements can improve strength development of mortar mixes, especially if the pozzolan contains substantial proportions of mineral oxides. In early strength investigation of the reactivity of siliceous rocks, Alexander (1960) found that siliceous materials such as quartz and basic or devitrified volcanic rocks, which were not regarded as likely sources of active pozzolana, were highly reactive when ground to ultra-fine powders. Alexander attributed the phenomenon to the presence of a distributed layer of highly reactive material which is formed on the surface of siliceous mineral particles as a result of prolonged grinding.

Greenberg (1961) found that for different siliceous materials with different surface areas, the reaction rate with calcium hydroxide solution did not show a significant correlation with the surface areas of the siliceous materials. Costa and Massazza (1974) studied six commercial Italian pozzolanas with different surface areas. They observed that the correlation between reactivity (as measured by combined lime) and surface area was valid only before 7 days, and that the activity of the pozzolanas depended on the content of $\mathrm{R}_{2} \mathrm{O}_{3}$. In subsequent research, Rossi and Forchielli (1976) did not find any correlation between surface area and reactivity with lime for the same materials examined by Costa and Massazza. An extensive examination of the strength of 22 pozzolanas indicated that there was no general correlation between the compressive strength at 28 days or 60 days and the surface area determined either by Blaine or BET method (Chatterjee 1967). Day and Shi (1994), by studying the effect of grinding on the strength development of natural pozzolana from Central America, concluded that a good linear relationship existed, and showed that an increase of $1.5 \mathrm{MPa}$ can be expected for every $100 \mathrm{~m}^{2} / \mathrm{kg}$ increase in fineness. Their study included Blaine fineness in the range of 250 to $550 \mathrm{~m}^{2} / \mathrm{kg}$.

Most of the studies cited above used different natural pozzolanas with different surface areas. For such pozzolanas, fineness is not the only factor affecting the reactivity of the pozzolana. The chemical composition, mineral composition, glass content of the pozzolana and the cooling rate of the fused magma are also very important to reactivity. Thus, it is not surprising that a lack of correlation exists when one tries to establish a universal relationship between reactivity and fineness. On the other hand, it seems that no attempts have been made to study the effect of fineness on the strength of artificial pozzolanas. For an artificial pozzolana, fineness is not the only factor that controls the strength. In additions to those controlling the strength of natural pozzolana, the strength of an artificial pozzolana is also influenced by the temperature and duration of calcination and the degree of fineness. The research described in this paper is an examination of 


\section{EFFECT OF THE FINENESS OF ARTIFICIAL POZZOLANA (SAROOJ)}

the correlation between the Blaine surface area of an artificial pozzolan from Oman (Sarooj) and the strength development of artificial pozzolana-lime mixtures.

\section{Experimental Program}

Two types of artificial pozzolans (sarooj) were used in this study. One type of artificial pozzolan was provided by the Omani Ministry of National Heritage and Culture (designated in this paper WM) which was prepared in its factory in Nakhal town using a traditional method of production. Details of its method of production can be found elsewhere (Hago et al 1999, 1998, 1997, 1995). The other type of pozzolana was prepared in the laboratory by burning clays obtained from Al-Khod town in Oman (designated in this paper KH). The burning parameters (temperature and duration) were determined by using Differential Thermal Analysis (DTA). Chemical tests were performed on the clays to determine their suitability for pozzolana production following standard procedures. The samples were burnt at a temperature of $780{ }^{\circ} \mathrm{C}$ and duration of 73 minutes.

The pozzolana was ground in a small ball mill to six Blaine fineness between 2360 and 4900 $\mathrm{cm}^{2} / \mathrm{g}$ and then blended with hydrated lime in the proportion of pozzolana:lime $=3: 1$ by mass, and a water/pozzolana ratio of 0.5 by mass was used throughout. These proportions were determined from extensive optimization studies carried out during the first phase of the project (Hago et al 95). A commercial hydrated lime from Oman was used. The Blaine fineness of the artificial pozzolana was measured by using Air Permeability Apparatus following the standard procedure in the Omanian Standard OS26 (1981). The apparatus was carefully calibrated for the type of pozzolana used.

Preparation of the specimens was made at a standard room temperature of $20{ }^{\circ} \mathrm{C}$. The mixes were cast into $70 \mathrm{~mm}$ mortar cubes (according to OS26-1981), covered with plastic covers for 3 days, then moved into a humidity controlled room at a temperature of $20{ }^{\circ} \mathrm{C}$. After 14 days, the cubes were transferred to a curing tank and kept under water until the date of testing. The curing method was determined in the first phase of the project (Hago et al 95), considering the humid conditions of the Gulf, and the high water retentivity of the hydrated lime. Compressive strength was determined at ages of 7, 14, 28 and 90 days. At each age of testing, three specimens were tested for compressive strength, and the reported values in Figures 1-5 represent the average of three cubes at each age.

\section{Results and Discussion}

Designation of samples of two types of pozzolana WM and KH are given in Table 1. The variation of compressive strength for the six lime-pozzolana mortars from Wadi Al-Mawail clays (WM) are given in Figures 1 and 3 while the corresponding ones for the six mixes from Al-Khod $(\mathrm{KH})$ are shown in Figures 2 and 4, for various degrees of fineness. In general, the compressive strength for all mixes in the KH group are higher than those in the WM group for all ages and for all degrees of fineness, as can be seen from Figures 1 and 2. This would be expected as was indicated by the chemical analysis of the two soils given in Tables 2 and 3, since the sum $\mathrm{SUMO}_{2}$ for the $\mathrm{KH}$ clays is higher than that for WM clays. Figure 1 also shows that a higher gain in strength for this type of pozzolana is not actually associated with a high degree of fineness, contrary to what one expects from a pozzolana. However, Figure 2 for the KH pozzolana indicates a reasonable reaction with the increase in fineness at all ages, although with differing rates.

The variation of the compressive strength of the mortars with Blaine fineness is shown in Figures 3 and 4 for the two types of pozzolana tested in this research, WM and KH. As can be seen from the Figures, the fineness of the pozzolan does influence the development of compressive strength and the ultimate strength of the pozzolana. However, an increase in the fineness of the artificial pozzolana has the general effect of increasing the strength of the mix in a nonlinear manner for ages from 7 to 90 days. The influence is quite different for the two types of pozzolana 


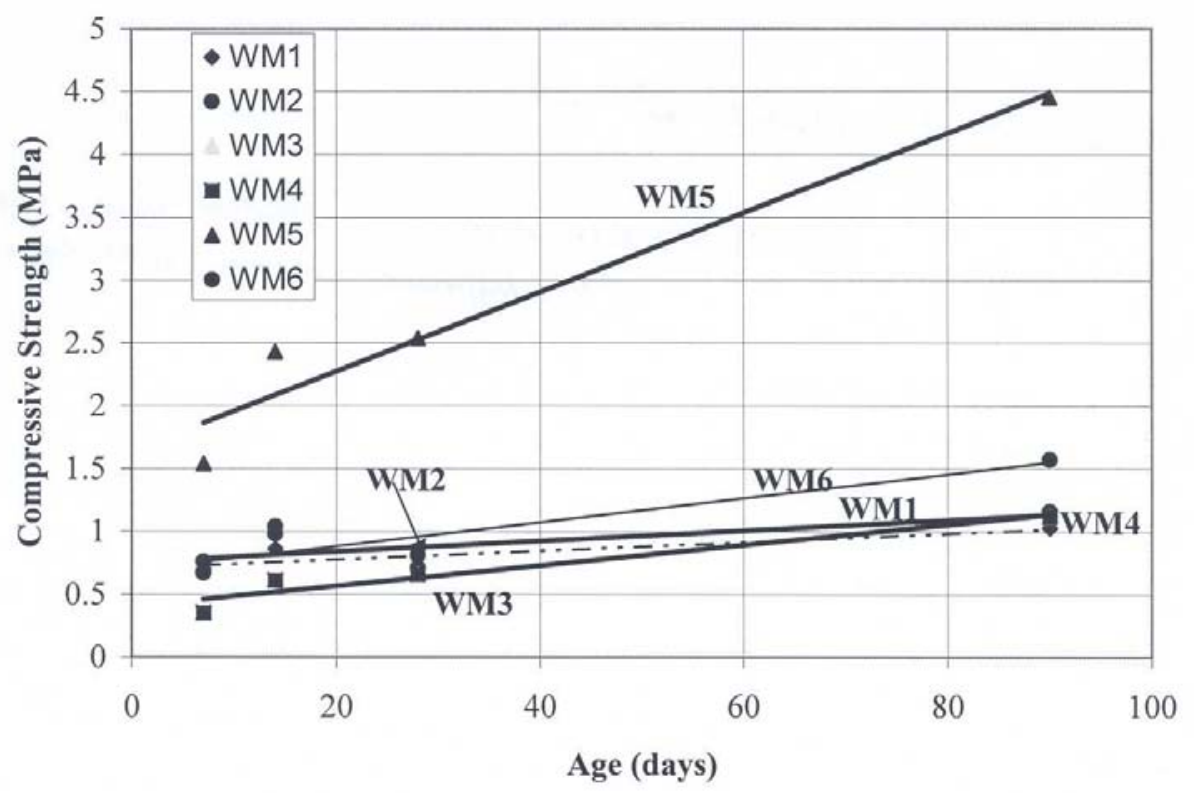

Figure1: Variation of strength with age for different fineness (WM Sarooj).

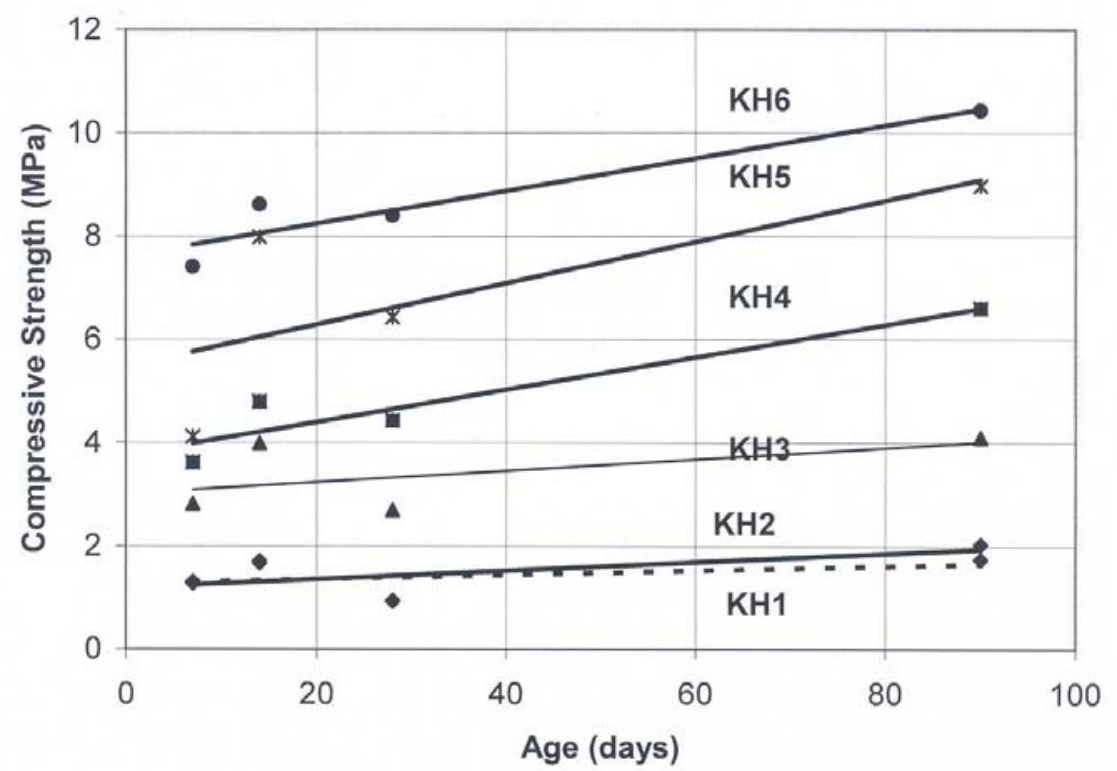

Figure 2: Variation of strength with age for different fineness (KH Sarooj). 


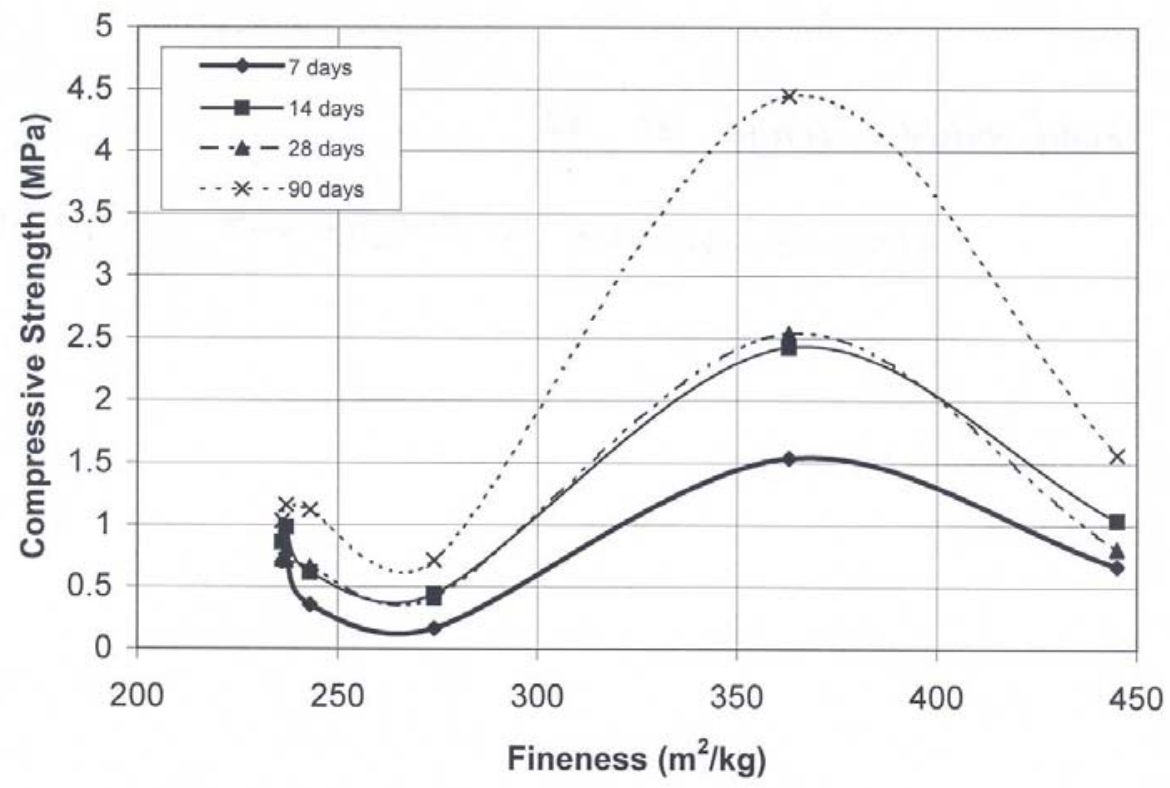

Figure 3: Variation of strength with fineness (WM Sarooj).

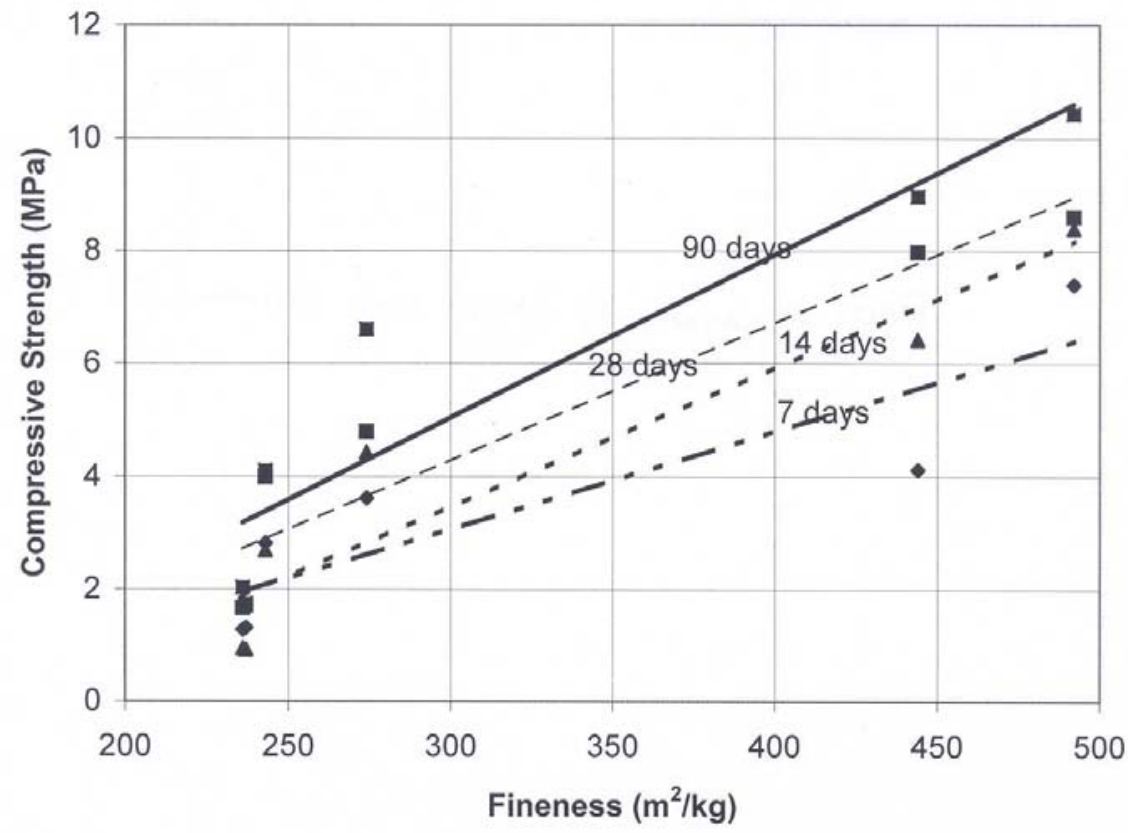

Figure 4: Variation of strength with fineness (KH Sarooj). 


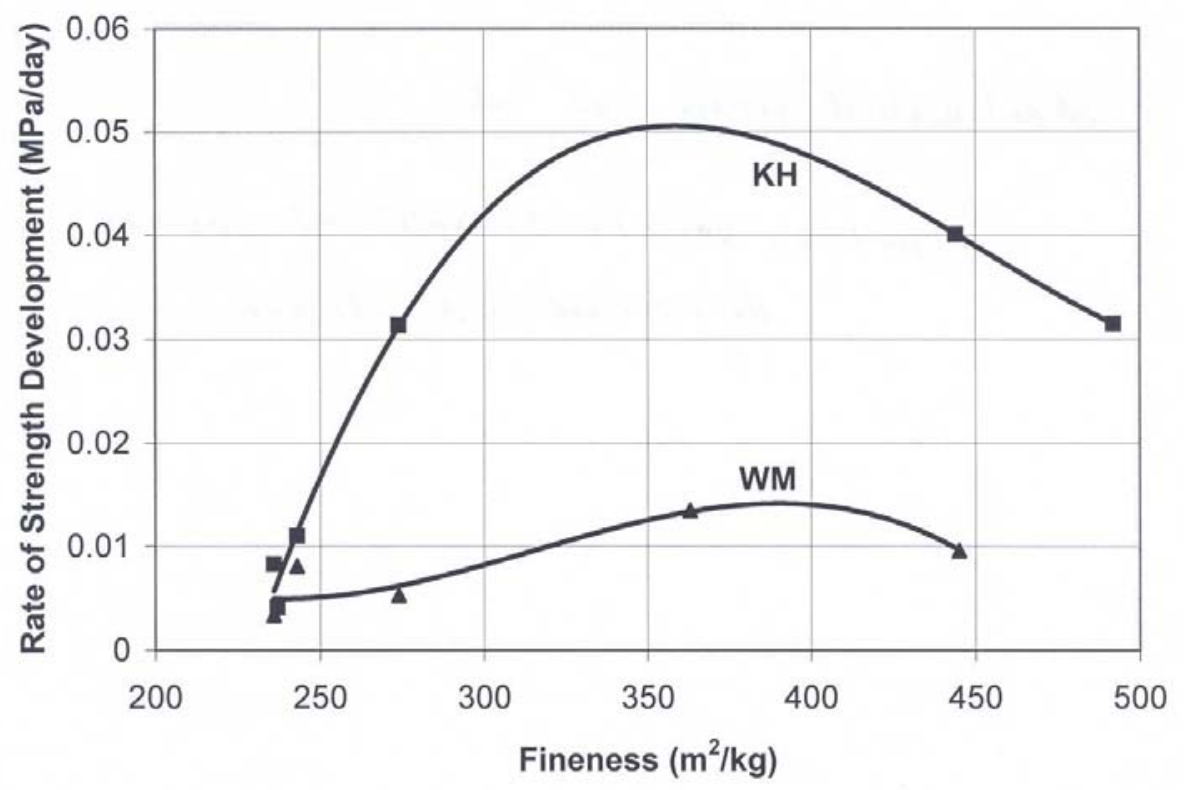

Figure 5: Variation of rate of strength development with fineness.

considered. For the WM pozzolana, no regular pattern can be identified, but an optimum fineness exists for which the strength is maximum. This comes around $375 \mathrm{~m}^{2} / \mathrm{kg}$ at all ages. For the $\mathrm{KH}$ pozzolana, a regular pattern can be identified. A greater influence is felt for fineness in the range of $230-275 \mathrm{~m}^{2} / \mathrm{kg}$, followed by a gradual increase for larger degrees of fineness. The influence of fineness is better illustrated by plotting the variation of the rate of development of compressive strength (obtained by least squares fit of the data in Figures 1 and 2) versus the Blaine fineness, as shown in Figure 5. From this Figure, it can be seen that little effect is produced on the low type pozzolana WM, while for the other type of pozzolana $(\mathrm{KH})$, we can distinguish two ranges of strength development. Up to a fineness of $275 \mathrm{~m}^{2} / \mathrm{kg}$, the slope of the curve is very high. Within this range, there is a rapid increase in the strength, followed by a gradual slowdown. In the latter range (i.e. beyond a fineness of $275 \mathrm{~m}^{2} / \mathrm{kg}$ ), the increase in the rate of strength development is not very much. At the end of the first phase, the rate of strength development increases by seven folds that at a fineness of $230 \mathrm{~m}^{2} / \mathrm{kg}$, compared to only 2.3 folds by the end of the second phase. By considering the high cost of grinding the pozzolana to this degree and the associated high water demand that adversely affects the strength, it does not appear appropriate to carry on grinding to fineness greater than $350 \mathrm{~m}^{2} / \mathrm{kg}$ for sarooj-lime mixtures.

Table 1: Designation of the samples tested and their degree of fineness.

\begin{tabular}{|c|c|c|c|}
\hline \multicolumn{2}{|c|}{ WM Sarooj } & \multicolumn{2}{|c|}{ KH Sarooj } \\
\hline Sample & Fineness $\left(\mathrm{cm}^{2} / \mathrm{g}\right)$ & Sample & Fineness $\left(\mathrm{cm}^{2} / \mathrm{g}\right)$ \\
\hline WM1 & 2360 & KH1 & 2360 \\
\hline WM2 & 2370 & $\mathrm{KH} 2$ & 2370 \\
\hline WM3 & 2430 & KH3 & 2450 \\
\hline WM4 & 2740 & KH4 & 2740 \\
\hline WM5 & 3630 & KH5 & 4440 \\
\hline WM6 & 4450 & KH6 & 4920 \\
\hline
\end{tabular}




\section{EFFECT OF THE FINENESS OF ARTIFICIAL POZZOLANA (SAROOJ)}

Table 2: Chemical composition of artificial pozzolana from Al-Khod clays.

\begin{tabular}{|l|l|l|l|l|l|l|l|}
\hline $\mathrm{SiO}_{2}$ & $\mathrm{Al}_{2} \mathrm{O}_{3}$ & $\mathrm{Fe}_{2} \mathrm{O}_{3}$ & $\mathrm{CaO}$ & $\mathrm{MgO}$ & $\mathrm{K}_{2} \mathrm{O}$ & $\mathrm{Na}_{2} \mathrm{O}$ & $\mathrm{SUMO}_{2} *$ \\
\hline 46.9 & 8.3 & 5.6 & 12.7 & 2.5 & 0.9 & 1.2 & 60.8 \\
\hline
\end{tabular}

$* \mathrm{SUMO}_{2}=\mathrm{SiO}_{2}+\mathrm{Al}_{2} \mathrm{O}_{3}+\mathrm{Fe}_{2} \mathrm{O}_{3}$

The effect of fineness on the workability and setting time of the mortars was also observed here. In general, great deterioration in workability was observed with the increase in the surface area of the pozzolana, since a fixed quantity of water was used in the preparation of the mixes. No attempts were made to correct the workability, but it was realized that, an increase in water demand results in loss of strength. For the weaker pozzolana samples WM, the effect on workability of the fineness is less than that on the workability of $\mathrm{KH}$ pozzolana. For both types of pozzolana, a reduction in the setting time of the mortar was obtained with the increase in fineness.

Table 3: Chemical composition of artificial pozzolana from Wadi Al-Mawail clays.

\begin{tabular}{|l|l|l|l|l|l|l|l|}
\hline $\mathrm{SiO}_{2}$ & $\mathrm{Al}_{2} \mathrm{O}_{3}$ & $\mathrm{Fe}_{2} \mathrm{O}_{3}$ & $\mathrm{CaO}$ & $\mathrm{MgO}$ & $\mathrm{K}_{2} \mathrm{O}$ & $\mathrm{Na}_{2} \mathrm{O}$ & $\mathrm{SUMO}_{2} *$ \\
\hline 33.5 & 7.12 & 2.46 & 22.74 & 8.43 &. &. & 43.08 \\
\hline
\end{tabular}

$* \mathrm{SUMO}_{2}=\mathrm{SiO}_{2}+\mathrm{Al}_{2} \mathrm{O}_{3}+\mathrm{Fe}_{2} \mathrm{O}_{3}$

\section{Conclusions}

The main conclusions derived from this study that examined two artificial pozzolanas can be summarized as follows:

1. The properties of artificial pozzolana/lime mixes are greatly affected by the degree of fineness of the pozzolana obtained by grinding the pozzolana.

2. For low grade pozzolana, the ultimate strength of the mortar will not be affected significantly by increasing the fineness, whereas for other types of pozzolana, the strength is greatly affected.

3. The rate of strength development increases with increase in fineness for good pozzolanas at all ages. A sharp increase occurs for surface areas up to $275 \mathrm{~m}^{2} / \mathrm{kg}$. Increasing the fineness beyond this limit, produces only a mild increase in the rate of strength development, resulting in insignificant increase in strength.

4. The setting time and the workability of the mortar reduce with the increase in fineness of the pozzolana. The effect is less for low reactivity pozzolanas. However, the consistency is not significantly affected by increasing the fineness for both types of pozzolana.

In general terms, whether for low reactivity pozzolan or high reactivity pozzolan, a surface area of about $350 \mathrm{~m}^{2} / \mathrm{kg}$ seems to be an optimum value in order to get the best strengths for the mixes studied here.

\section{Acknowledgement}

This research is partly supported by Sultan Qaboos University, for which the authors are indebted. The cooperation of the Ministry of National Heritage and Culture is gratefully acknowledged.

\section{References}

ACI Committee 232, 1994. Use of Natural Pozzolans in Concrete: American Concrete Institute Materials Journal, July-August: 410-426. 
AL-RAWAS, A.A., HAGO, A.W., CORCORAN, T.C. and AL-GHAFRI, K.M., 1998, Properties of Omani Artificial Pozzolana (Sarooj): Applied Clay Science Journal, 13(4): 275-292.

ALEXANDER, K.M., 1960. Reactivity of ultrafine powders produced from siliceous rocks: Journal of American Concrete Institute, 57: 557-569.

CHATTERJEE, M.K. and LAHIRI, D., 1967. Pozzolanic activity in relation to specific surface of some artificial pozzolans: Transactions of Indian Ceramic Society, 26:65-74.

COSTA, U. and MASSAZZA, F., 1974. Factors affecting the reaction with lime of some natural Italian pozzolans: Cemento, 74(4):131-139.

DAY, R.L. and SHI, C., 1994. Influence of the fineness of pozzolan on the strength of lime naturalpozzolan cement pastes: Cement and Concrete Research Journal, 24(8):1485-1491.

GREENBERG, S.A., 1961. Reaction between silica and calcium hydroxide solutions, Kinetics in the Temperature range $30-85^{\circ} \mathrm{C}$. Journal of Physical Chemistry, 65:12-16.

HAGO, A.W., AL-RAWAS, A.A., and AL-HARTHY, A.S. 1995. The Omani Sarooj, Sultan Qaboos University, First report on the Omani Sarooj (classified).

HAGO, A.W., and AMER AL-RAWAS, 1997. Properties of the Omani Sarooj: Engineering Journal of the University of Qatar, 10: 81-91.

HAGO, A.W. and AMER AL-RAWAS, 1999. An investigation into the traditional method of production of Omani Sarooj: Sultan Qaboos University Journal of Science and Technology, 4:35-43.

LEA, F.M., 1971. Chemistry of cement and concrete, Chemical Publishing, Inc., pp414-453.

OMANIAN STANDARD OS26, 1981. Methods of Testing Cement-Physical Tests-Determination of Fineness: Ministry of Commerce and Industry, Directorate General for Specifications and Measurements.

ROSSI, G. and FORCHIELLI, L.,1976. Porous structure and reactivity with lime of some natural Italian pozzolans: Cemento, 76(4): 215-221.

Received 13 November 2001

Accepted 24 September 2002 